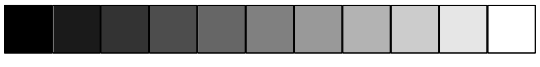

GEOUSP - Espaço e Tempo, São Paulo, № 16, pp. 193 - 209, 2004 

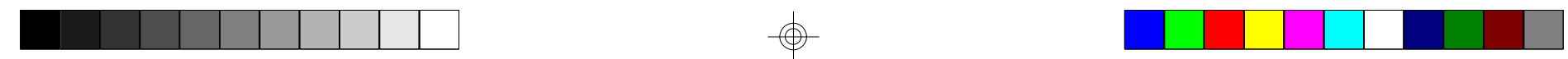

GEOUSP - Espaço e Tempo, São Paulo, № 16, pp. 193 - 209 , 2004

\title{
PAÍSES DO LESTE EUROPEU: AS REFORMAS PARA UMA ECONOMIA DE MERCADO - O CASO DA HUNGRIA
}

\author{
Regina Salvador*
}

\section{I - Introdução}

Desde a queda do Muro de Berlim (a 10 de Novembro de 1989) e a desintegração do COMECOM (Maio de 1991) que os novos Estados da Europa Central, do Báltico, a Rússia e outros territórios da ex-URSS têm desenvolvido esforços hercúleos no sentido de orientarem as suas economias pelas leis do mercado e não mais pelo planeamento centralizado que as regeu durante décadas.

Nos primeiros anos, esta transformação económica foi acompanhada por uma profunda instabilidade nos preços e na produção. Porém, a implantação de programas de estabilização económica por parte do FMI e do Banco Mundial ajudaram alguns países, criando um ambiente propício à introdução de profundas reformas estruturais.

Mas os desafios ainda se mantêm enormes como o testemunham a situação económica e social de países como a Albânia, a Bulgária ou a Roménia (entre 1996 e 1997) ou a grave crise russa de 1998.

Desemprego, corrupção e criminalidade fazem ainda parte do dia-a-dia de grande parte destes "países em transição". E, em alguns deles, o nacionalismo descontrolado e a xenofobia, fenómenos até então controlados pelo comunismo, agravam ainda mais as profundas crises económicas e sociais.
Assim, a nova ordem política e económica ainda continua frágil em alguns países que adoptaram o modelo ocidental de economia de mercado, apesar de as reformas conducentes a este novo modelo estarem a ser implementadas, em menor ou menor grau, em todos os países em transição.

\section{II - As reformas para a transição económica}

A transição económica dos países de economia centralizada constitui um processo histórico que implica profundas mudanças em quase todos os aspectos da sociedade. O seu principal objectivo é a adesão dos países, até então de planeamento económico centralizado, ao capitalismo: é a despolitização da economia, a activação dos mercados, a privatização da propriedade e dos meios de produção.

A maioria dos analistas da transição económica, nomeadamente Jeffrey Sachs, da Universidade de Harvard, propôs o "shock therapy model", uma receita para uma transição de sucesso que converge nos critérios objectivos que têm sido "impostos" pelas instituições de Bretton Woods:

1) Liberalização da actividade económica, dos preços e dos mercados, que permita a alocação dos recursos para a sua utilização mais eficiente;

\footnotetext{
* Doutorada em "Espaço e Economia" pela Universidade Nova de Lisboa (1993) e em "Economic Development" pela University of London 1998). Professora associada com agregação da Universidade Nova de Lisboa, onde é responsável pelas cadeiras de "Teorias e Políticas de Desenvolvimento" e "Geoeconomia da Europa" a nível de Licenciatura e "Organização Espacial das Sociedades" e "Políticas de Desenvolvimento", nível de Mestrado. "Visiting Professor" da Universidade de São Paulo (Brasil) e da "Catholic University of San Diego" (EUA). Conferencista do Instituto Superior Técnico (IST) no Mestrado em "Engenharia e Gestão da Tecnologia" e no Programa IMPACT (desenvolvido com a "University of Texas at Austin", EUA). E-mail: regleo@netcabo.pt
} 
2) Estabilização proporcionada pelo desenvolvimento de instrumentos macroeconómicos orientados para a economia de mercado;

3) Descentralização da propriedade e privatização da actividade económica;

4) Desenvolvimento de um quadro legal e institucional que defenda os direitos de propriedade privada, balizado por uma reorientação do papel do Governo na economia.

Todos estes critérios objectivos, que se sintetizam na Figura 1, podem ser quantificados, pelo que a questão essencial na análise das várias experiências de transição é saber a partir de que ponto se pode considerar que a tão almejada economia de mercado foi (ou não) alcançada.

Por outro lado, estes critérios ou "ingredientes" têm em conta o grau de aplicação de políticas sistemáticas de liberalização dos preços, do comércio, dos mercados financeiros (incentivo ao investimento privado), de reformas fiscais e monetárias e de criação e consolidação de fortes instituições de apoio ${ }^{1}$.

FIGURA 1 - Os "ingredientes" da transição económica

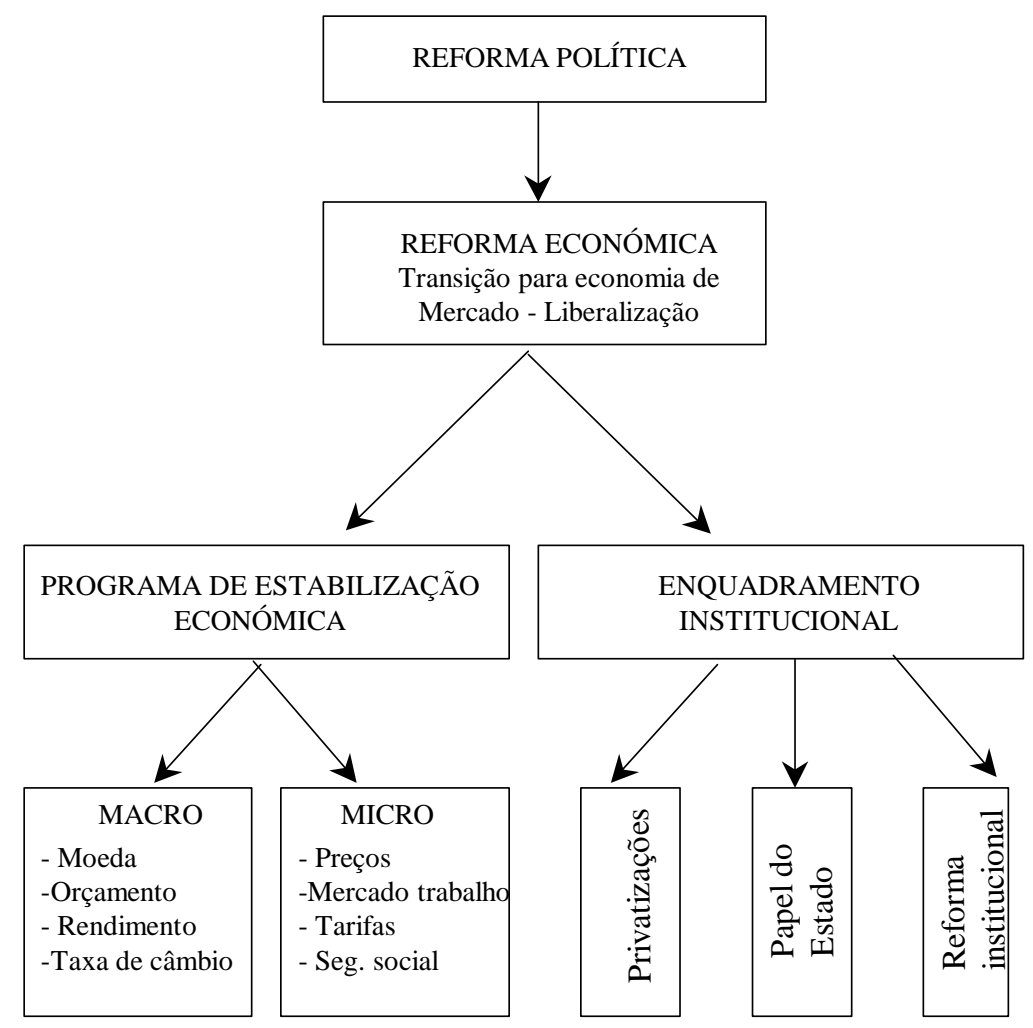




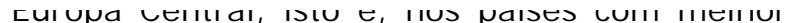
performance económica e índices de crescimento.

Alguns dos países em transição têm registado êxito na abertura das suas economias e na reorientação das exportações para os mercados internacionais. As exportações e os serviços têm sido os motores do crescimento das economias em transição. A produção aumentou mais nos países com maior crescimento médio das exportações, o que sugere que a abertura das economias e a promoção das exportações são importantes determinantes do crescimento.

Os países em transição têm registado êxito na abertura das suas economias e na reorientação das exportações para mercados internacionais. Vários países diversificaram rapidamente as exportações e alguns inverteram a tendência de queda do valor unitário das exportações de máquinas, o que indica que a qualidade dos seus produtos está a melhorar.

Alguns analistas defendem que seja qual for o ritmo da liberalização, o comércio externo e as transacções cambiais devem ser liberalizados mais lentamente do que os mercados internos, com o intuito de diminuir a queda inicial do emprego e da produção.

A liberalização rápida do comércio pode ser benéfica: a Estónia eliminou as barreiras à exportação, bem como as restrições quantitativas à importação, o que permitiu uma

\section{2. - A estabilização econór}

A lição menos controve surpreendente da transição económica estabilização económica sustentada ( entre outros factores no controlo da no incentivo à poupança e ao investin fundamental.

As economias em transição enfren geral, graves problemas com a implen dos programas de estabilização impos FMI. Um destes problemas cons determinação do tipo de taxa de câm ou flexível) que se deve utilizar na rec inflação e dos custos da transição.

As várias experiências de $\mathrm{tr}$ demonstraram que, tanto as taxas de fixas (caso da Croácia, Estónia, Hu Polónia no início da transição) como : de câmbio flexíveis (Albânia, Eslovénia, ou Moldávia) permitem consideravelmente a inflação.

No início do processo de trans taxas de câmbio fixas constitur instrumento válido da política de estak A troca automática de divisas por moed uma taxa de câmbio fixa permite que os económicos reponham mais rápida e fa os seus saldos reais. Todavia, com o aı liberalização, as taxas de câmbio f revelam-se mais eficientes na redı inflação e na estabilização económica. 
ausência de proprietários "fortes". Tal situação tem conduzido a que alguns mutuários, perante a subida das taxas de juros, não reduzam o crédito mas aumentem cada vez mais o seu endividamento. Este endividamento crescente origina juros reais muito altos, o que poderá originar graves crises financeiras.

Assim, um dos aspectos cruciais da estabilização é a necessidade de resolução do problema da insolvência dos bancos e das empresas, acompanhada da intensificação da eficiência e da concorrência dos mercados financeiros e da intermediação financeira. Assim se justifica que em diversos países em transição se verifique a exclusão dos leilões de crédito das instituições bancárias mais instáveis.

Neste contexto, a reforma do sector financeiro é fundamental para a promoção do crescimento, permitindo o reforço da intermediação financeira e o aumento da eficiência na alocação dos recursos financeiros.

Porém, na maior parte dos países em transição a criação de um sistema bancário competitivo e aberto às instituições financeiras estrangeiras encontra-se ainda numa fase muito incipiente.

Outro aspecto da estabilização económica é, como referimos, o incentivo à poupança interna dos agentes económicos como forma de aumentar o investimento interno, essencial na transição, já que o investimento estrangeiro

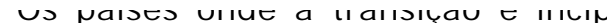
têm ainda pela frente a árdua tarefa de : as suas economias da instabilidade econı e do controlo estatal que continua a dificu transição.

É assim necessário encontrar e m políticas macroeconómicas eficazes, de mı permitir o crescimento económico susten seja através de taxas de câmbio fixa flexíveis, de taxas de juros baixas e da solv das instituições bancárias.

II.3 - A descentralização da proprie e a privatização da actividade económic

A descentralização da propriedad privatização da actividade económica foi/é outra reforma necessária.

Diversos autores citam Adam Smit sua obra "An Enquiry into the Wealth of Nat publicada em 1776), para demonstrar c ideia de "privatização" estava já presen pensamento económico clássico, embora s aplicação que viria a ter dois séculos mais 1

Para Adam Smith, a venda de terr Coroa libertaria dinheiro que, ao ser util no pagamento da dívida pública, aumenta rendimentos. Por outro lado, os terr agrícolas ao se tornarem propriedade pr passariam a ser melhor explorados.

Vários estudos desenvolvidos, que países desenvolvidos com economia mercado consolidadas quer em paíse: 
públicas (em França, por exemplo) que se revelam mais produtivas do que muitas empresas que se renderam ao capitalismo "selvagem".

Por outro lado, em todas as economias em transição a privatização estimula a criação de instituições fundamentais: é o caso dos mercados de capitais, de sistemas jurídicos liberais ou de profissões relacionadas com a actividade empresarial. Como diz Lombardini, "the conditions must be created for both more efficient markets and a more efficient state: privatisation is only one of the structural changes required" (1992: 117).

Os direitos de propriedade constituem assim a alma da estrutura de incentivos da economia de mercado.

No modelo de planeamento centralizado, as empresas estavam protegidas da concorrência e funcionavam segundo a "economia de escassez" onde tudo o que produziam era rapidamente tragado pelos consumidores.

Com a transição económica, passou-se de um regime baseado nas transferências e nos subsídios para um novo sistema, baseado no risco, na disciplina financeira e na procura do lucro.

A transição exige reformas eficazes que permitam a disciplina fiscal e favoreçam a concorrência, a entrada de novas empresas e o encerramento de empresas que não sejam exemplo, na Rússia a maioria das qu Estado foi privatizada mediante a sua $\mathrm{Cl}$ em grandes sociedades anónimas, ap esta não ser a forma de propriedaı eficiente para a agricultura. Neste mes estima-se que cerca de 16 biliões de di equivalente a $80 \%$ do PIB), é desviad mercado informal e continuam a cc rendas para determinadas elites (rent s

Por outro lado, a privatiza empresas de pequena dimensão mo: muito mais fácil que a das grandes emr maioria das empresas de pequena $d$ dedica-se ao comércio e aos si actividades de tecnologia simples e acesso, enquanto que as de grande $d$ enfrentam obstáculos relacionados grande volume de capital, a necessidade reestruturação profunda e as deficiên áreas da regulamentação e da gestão.

Entre os sectores onde as priva têm sido proteladas por mais tempo se, evidentemente, os serviços públicos estruturas (electricidade, telecomunicaç natural, oleodutos, abastecimento d portos e aeroportos). A privatizaçãc sectores apresenta problemas específ empresas são de grande porte, de intensidade de capital e, muitas ve: consideradas estratégicas do ponto de Defesa Nacional. 
Instıluiçoes necessıtam ue ser acompannauas por um Estado forte que assuma um novo papel estratégico na economia. O Estado é imprescindível na transição - "the efficiency of markets depends to a large extent on the efficiency of certain services provided by the state" (Lombardini, 1992: 118) - e a credibilidade do seu empenho reformador é crucial.

O Estado deve ditar as regras do jogo da economia de mercado, nomeadamente em sectores estratégicos como a segurança social e o direito de concorrência. O papel do Estado na economia assume-se assim numa óptica de complementaridade.

Por outro lado, a criação de um quadro institucional eficiente, onde impere a abertura ao exterior e a transparência, é a chave do sucesso para uma das reformas estruturais - a privatização. De facto, "to perform their tasks, governments in market economies need some well-developed institutions run by competent individuals and guided by appropriate incentives" (Idem: 118).

O fim das regulamentações discriminatórias do Estado e a criação de instituições eficientes reduzem o risco, criam um ambiente favorável ao investimento e fomentam a iniciativa privada.

Por outras palavras, a criação de um "market-friendly environment" encoraja a poupança, o investimento privado, o crescimento do respeito pela propriedade privada promoção de um enquadramento institur favorável.

\section{III - Balanço de uma década de transição a economia de mercado \\ III.1 - A heterogeneidad $\epsilon$ adaptação às novas regras do jogo}

A nova ordem (ou desordem?) é frágil e incipiente em alguns países do Europeu.

A própria composição interna territórios pós-comunistas representi "puzzle" de difícil ordenação, com dist peças de natureza étnica, religiosa, sor económica.

Verificamos que os países mais pró: da Europa Ocidental e com maior experi de democracia política e económica destaque para a Hungria e Polónia), revelado uma maior capacidade de adap às novas "regras do jogo". O mesmo podemos dizer dos países geograficar mais distantes da Europa Ocidental: neste efeitos do planeamento centralizado são profundos (para além de séculos de feudá ou de "despotismo asiático").

Segundo o Banco Europeu Reconstrução e Desenvolvimento (EBRD: 1999, o PIB da ex- URSS foi cerca de $65 \%$ 1989. 

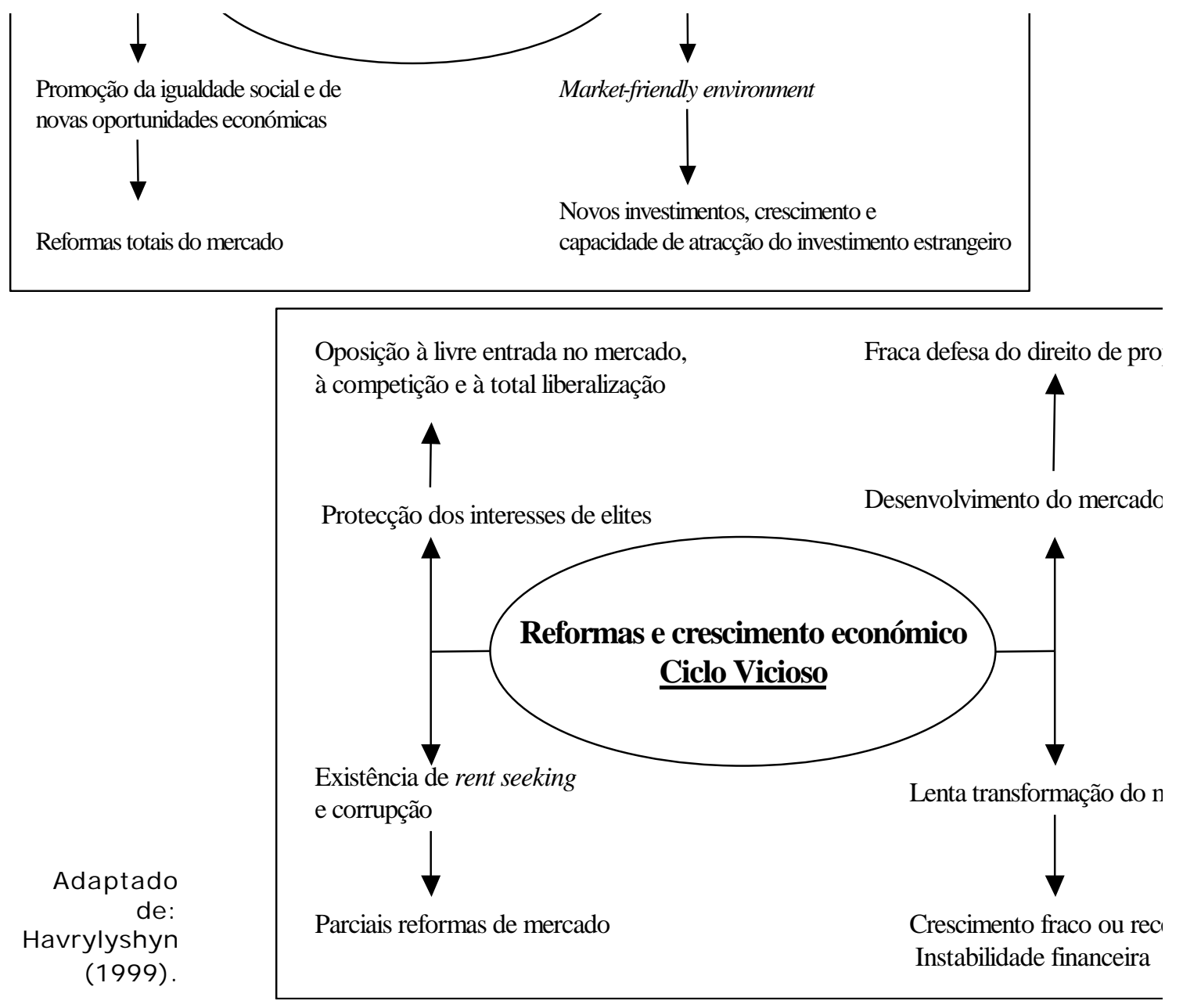
"capitálismo selvagem", ém todó o seu esplendor: crime, corrupção, falta de estabilidade económica, crise social e rent seeking...

No início da transição, países como a Albânia, a Bulgária ou a Roménia registaram um período de crescimento, que durou entre 3 e 5 anos, para mais tarde entrarem em profunda recessão, dada a ausência de importantes reformas estruturais. Países como a Rússia, a justifica que este país seja o favorit Professor Jeffrey Sachs, o famoso econo neoliberal da New York University, recomenda desde o início da transição "terapia de choque" para os países comunistas.

Todavia, mesmo para os al exemplares da Europa Central - Polól Hungria -, o percurso para uma transição

FIGURA 3 - Crescimento nos países em transição (1991=100)

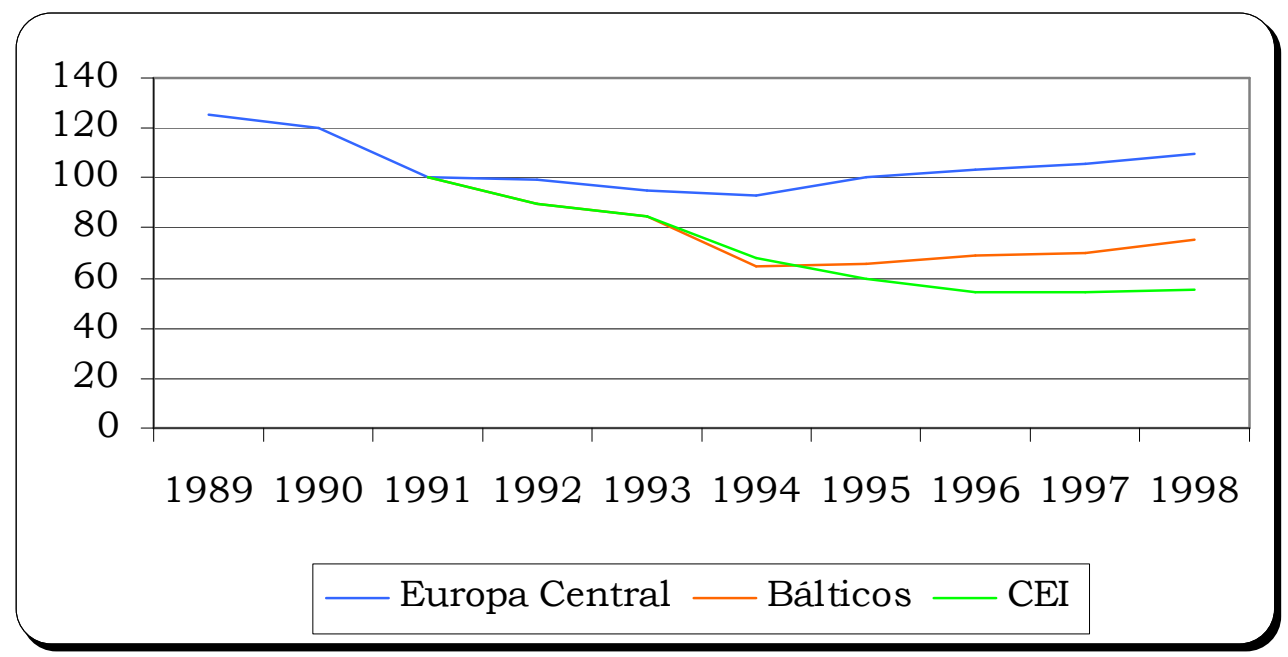

Fonte: EBRD (1999). 
registado nos países que conseguiram a estabilização económica, nomeadamente através do controlo da inflação.

Alguns países não registam sucesso nas reformas da transição dadas as desfavoráveis condições iniciais (caso do sistema industrial do período de planeamento centralizado). Com efeito, são em parte as favoráveis condições iniciais que explicam o bom caminho para a transição seguido pelos países da Europa
A transição económica ter acompanhada por um rápido e $p$ aumento das desigualdades sociais. : estimativas da OCDE, a desigualdade s Europa de Leste, no Báltico, na Rúss outros territórios da ex-URSS au consideravelmente: em menos de 10 coeficiente de Gini aumentou de 25-28 $38^{5}$.

FIGURA 4 - Índice de Liberalização Económica (em 1997)

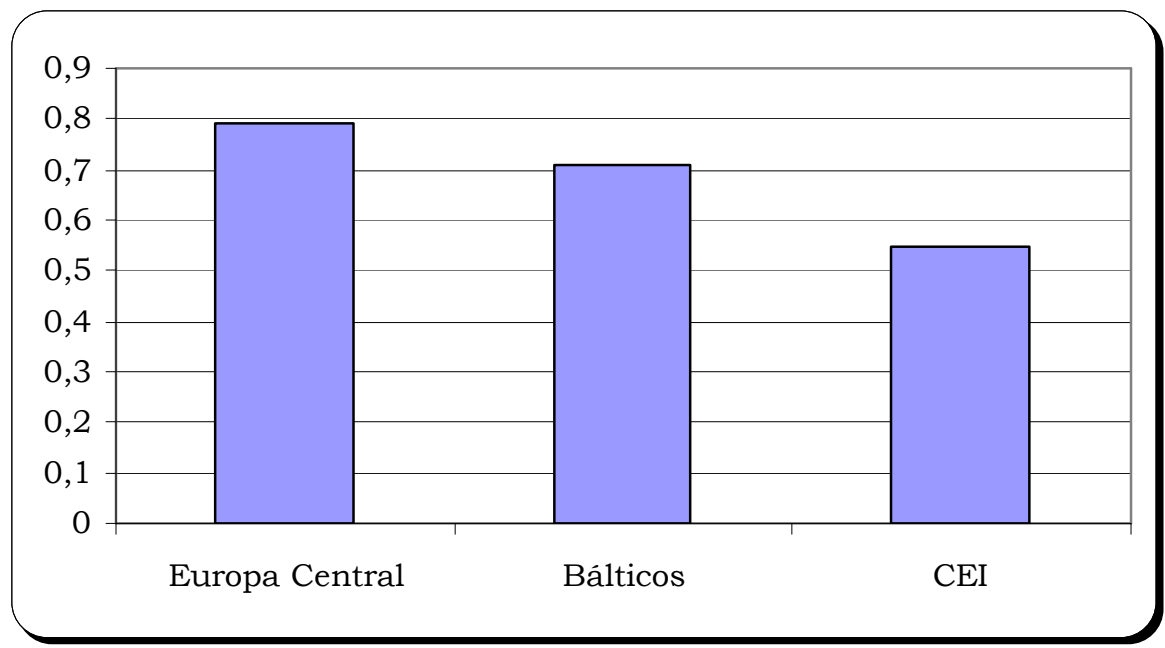

Fonte: Tanzi (1999). 


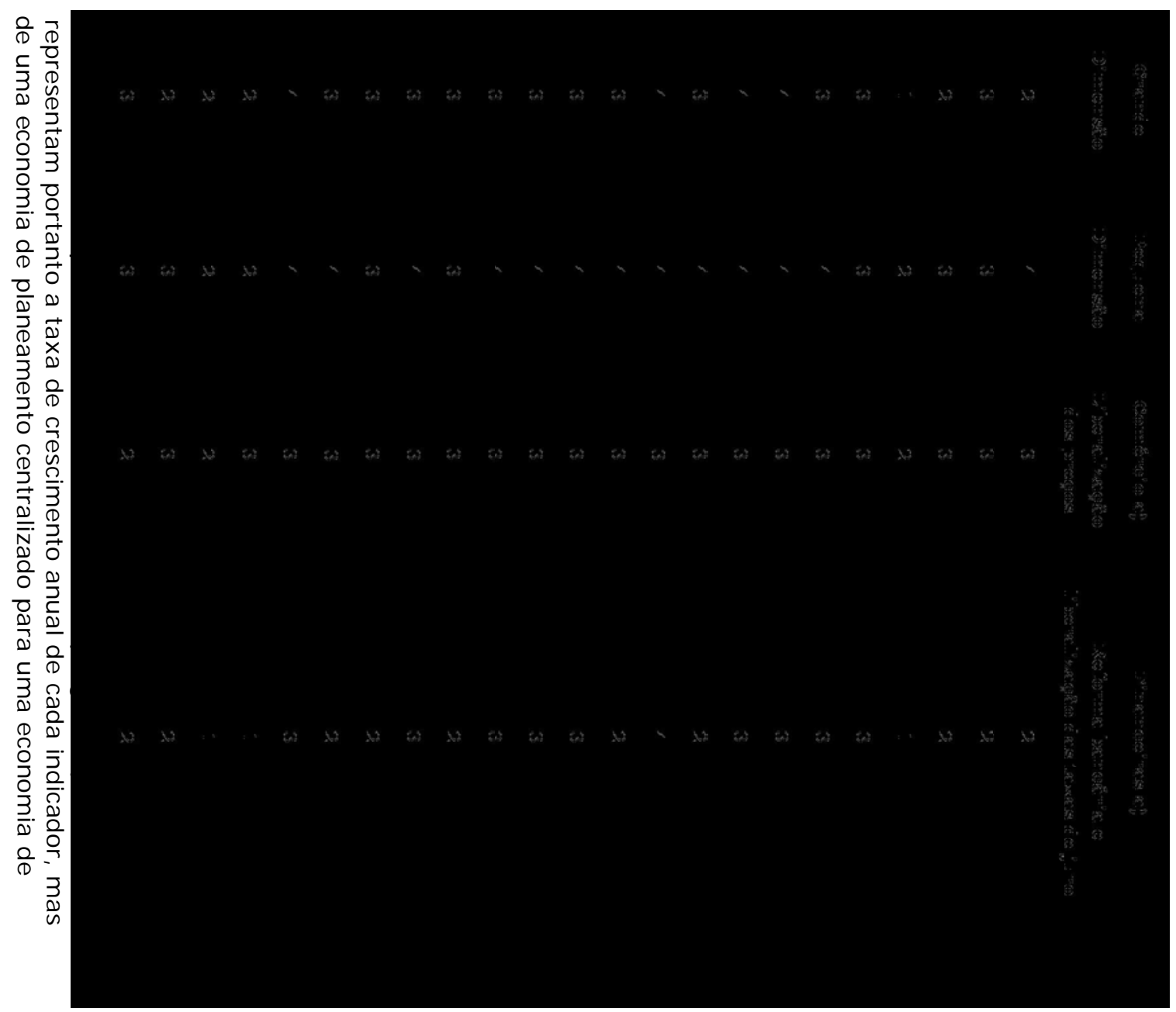


O padrão de vida na maioria dos países em transição caiu nas etapes inicias da reforma: - emprego reduziu-se e o desemprego aumentou, sobretudo nos países pertencentes à CEI, onde o ajustamento do mercado de trabalho foi feito através de demissões e onde as novas empresam privadas não foram capazes de assimilar todos os activos oriundos das empresas estatais.

Neste contexto, um aspecto importante da transição é a tentativa de resposta à seguinte questão: no geral, as populações sujeitas a um processo de transição económica estão ou não a viver melhor do que antes?

A forma em que os indivíduos foram envolvidos no processo de transição e os benefícios que daí podem retirar são fundamentais para que se alcance o referido ciclo virtuoso, logo uma transição bem sucedida.

O relatório do Banco Europeu para a Reconstrução e Desenvolvimento (BERD) de 2001 defende que o alívio da pobreza, o capital humano e a sua adaptação às necessidades dos mecanismos de mercado são fundamentais para o crescimento sustentado, o desempenho económico e a promoção da sustentabilidade política e da justiça social ou equidade.

Contudo, é óbvio que as etapas iniciais da transição acarretam custos sociais elevados - é o princípio do "no pain no gain" da transição.

De facto, no início da transição, verificase um agravamento das disparidades em as redes de protecção social e aliviar a

É decisiva a criação de um siste justo de distribuição dos rendiment riqueza.

Apesar de a pobreza ter aument primeiros momentos da transição, estabilizar nos países que retom crescimento.

Se considerarmos a variedade mui de produtos (sobretudo importados) e de consumo duráveis de alta qual disposição das populações, com o economia de escassez, podemos afirm: bem-estar das populações sujeitas à $t$ económica tem aumentado.

Por outro lado, através da liber económica e da descentralizaç propriedade, os indivíduos podem a riqueza pessoal através de cupons, ac empresas, pequenas empresas, te habitações.

A maior parte dos analistas da $t$ é portanto unânime em afirmar que, prazo, a única forma de combater a $\mathrm{p}$ o fomento do crescimento económico da introdução e consolidação de $r$ favoráveis às forças do mercado.

\section{IV - O caminho que ainda falta perco}

As experiências de transição economia de mercado que duram, há 
Todavia, pelo exposto conclui-se que ainda resta um longo caminho a percorrer para que o sucesso da transição seja efectivado na maior parte dos países de Leste.

Cinco obstáculos fundamentais continuam a ameaçar a transição de alguns países, sobretudo os do antigo bloco soviético:

1) O falhanço na construção das novas Nações, o que tem conduzido ao caos (exemplos da região do Cáucaso);

2) A dificuldade de acompanhamento, por parte de alguns países, da estabilização económica e consequentes ciclos de persistente inflação e desemprego elevados;

3) A insuficiente liberalização e privatização e, consequentemente, a corrupção, o crime, o rent seeking ou o crony capitalism;

4) O crescimento excepcional da economia informal, que incentiva a corrupção e enfraquece a credibilidade do mercado formal e das instituições públicas, impedindo o desenvolvimento do sector privado aberto e formal;

5) O desaparecimento repentino das instituições do planeamento centralizado, sem que antes tenham surgido instituições de mercado (por exemplo, diversos países desfizeram-se dos velhos sistemas de crédito agrícola e distribuição da produção sem criarem novos sistemas baseados no mercado).
Letónia e a Estónia.

Países como a Eslováquia, a Lituâr Roménia e a Bulgária precisam ainda de grandes esforços para se possam inseri chamadas economias de mercado funcion

Todavia, mesmo a Polónia, foi obrigi realizar algumas reformas, nos sectores ag e mineiro, nomeadamente.

A aposta na superação dos obstácı transição e a implementação das reforma descrevemos no início deste capítulo, aju os países em transição do Leste Europ futuros membros da União Europeia a cc as deficiências e desequilíbrios herdadc planeamento centralizado e a encont caminho certo do crescimento seguro, ráp sustentado.

A escolha exacta deste caminho der dos objectivos, do empenho e da consci das limitações de cada país...

\section{V - O Caso da Hungria \\ V. 1. - Enquadramento Geográf Breve Resenha Histórica}

A Hungria é um país localizado na $E$ Central, sem ligação com o mar. Faz frol com sete países: Eslováquia a norte, Ucrô nordeste, Roménia a leste, Croácia e Jugo (Sérvia e Montenegro) a sul, Eslovéı 

correspondente a áreas montanhosas, é coberta por florestas de caducifólias. No restante território predomina a actividade agrícola e as pastagens. em aglomerados urbanos, em 1998. A Budapeste, concentra cerca de 18, habitantes do país.

A Hungria é um país que aprese

FIGURA 1 - CENTRO DE BUDAPESTE

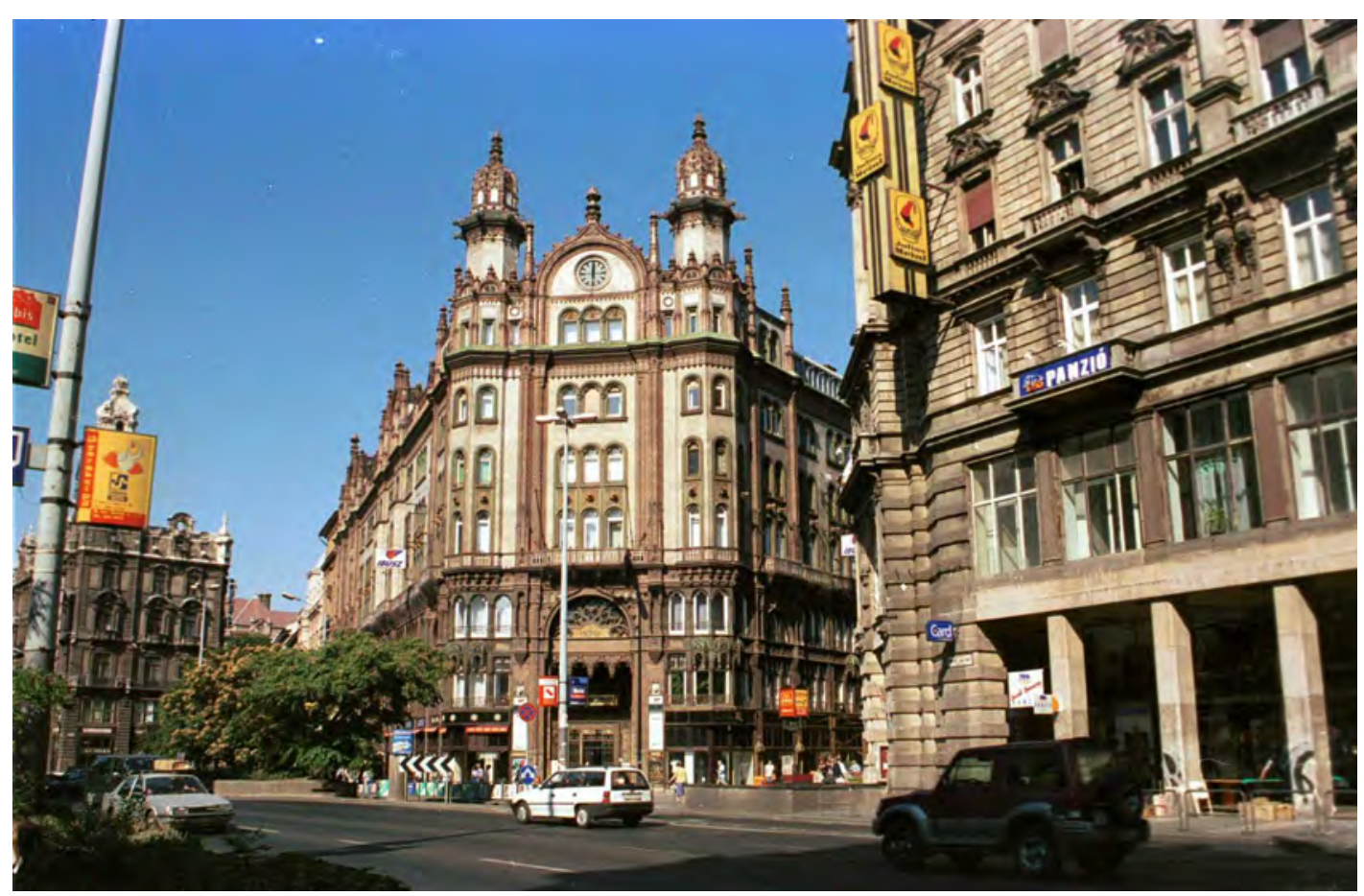


Em 1699, grande parte da Hungria é incorporada no império dos Habsburgos. Em 1849, após a eclosão de uma revolta que pretendia alcançar a independência, o Império dos Habsburgos torna-se numa monarquia dualista (Áustria-Hungria); em 1867, a Hungria obtém um estatuto em tudo semelhante ao da Áustria.

A derrota na I Guerra Mundial leva à queda do Império e à proclamação da República da Hungria, que perde cerca de dois terços do seu território e metade da população.

A Hungria entra na II Guerra Mundial ao lado da Alemanha Nazi na tentativa de recuperar os territórios perdidos. Em 1945 é invadida pelo Exército Vermelho e, em 1949, é instalado um governo comunista.

Em 1989 as eleições livres estabelecem um governo democrático e inicia-se o processo de transformação política e económica.

\section{V.2 - A Transição Económica}

A Hungria é normalmente apontada como o país que melhor efectuou a transição de uma economia de planeamento centralizado para uma economia de mercado.

Já em 1968 tinham sido adoptadas algumas medidas orientadas para o mercado, que ficaram conhecidas por "Novo Mecanismo Económico". Apesar da natural timidez de tais medidas, os anos 60 e 70 foram um período de produção agrícola e de bens de consumo. Ainda que a Hungria tenha sido o pri PECO a realizar reformas viradas $p a$ mercado, o que é facto é que a econom manteve controlada pelo Estado e I cooperativas, até finais dos anos 80 . Era o do estatuto da propriedade e das gra decisões económicas, como a afectaçã recursos, a concessão de crédito e de sub ou a origem das importações, qui mantiveram sob firme domínio estatal.

Apesar do crescente dinamismo do : privado, apenas em Março de 1990, c derrota dos comunistas nas eleições, é c Hungria conseguiu criar condições políticas caminhar definitivamente para uma econor mercado. Rapidamente foram tomadas $m \epsilon$ no sentido de liberalizar o comércio exterr preços, o investimento externo e inic processo das privatizações.

No período compreendido entre $1 \subseteq$ 1994 a transição para o mercado foi ma pelo crescimento negativo do Produto In Bruto (PIB). Esta situação surgiu da combi das reformas económicas com o colaps COMECON $^{4}$; contudo, a recessão económi menor do que na generalidade dos PECO. melhor comportamento da economia húı face às suas congéneres do Leste eur deveu-se, em grande parte, à já ref introdução de mecanismos de mercado (c 1968), que facilitaram a reestruturaçãc 
$\cup$ prucessu uas privalilaçues, illiciauu Ila primeira metade da década de 90, está praticamente terminado. O ritmo de privatizações foi elevado, passando de 1858 empresas estatais em 1990, para apenas 3 em 1999. Foi transferido para o sector privado grande parte da actividade económica do Estado, nomeadamente sectores estratégicos como a banca, as telecomunicações e a energia.

O diploma legal que dinamizou o processo das privatizações, pelo que ficou conhecido como "Lei das Privatizações", data de 1992 e foi modificado em 1995. Este diploma foi ainda sujeito a algumas alterações em Julho de 1997, entre as quais se destacam, a redução da participação máxima do Estado para $25 \%$ mais um voto ou para uma "golden share", com direitos preferenciais de voto.

Com esta medida, procurou-se estimular a reestruturação económica, modificar a organização empresarial, desenvolver a aquisição de "saber-fazer" e a aprendizagem de novas técnicas de gestão e vendas, fomentar o mercado de capitais e reforçar o papel dos investidores estrangeiros nas empresas húngaras. De referir ainda a importância do papel assumido pelo encaixe financeiro decorrente das privatizações na redução da dívida externa.

Em 1995, foi recriada a Agência Húngara de Privatização e Gestão do Património e Gestão do Estado (ÁPV Rt.), através da criação de uma sociedade anónima responsável pela gestão,

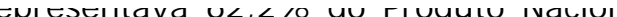
(PNB).

Dados de 2000 indicam um PIB $p$ em PPC (Paridades de Poder de Compr o terceiro mais alto de entre os PECO, Eslovénia e da República Checa.

Em 1996, a Hungria aderiu à OC[ Março de 1999 à NATO, prevendo- -se Maio de 2004, se torne membro de plen da União Europeia.

\section{HUNGRIA}

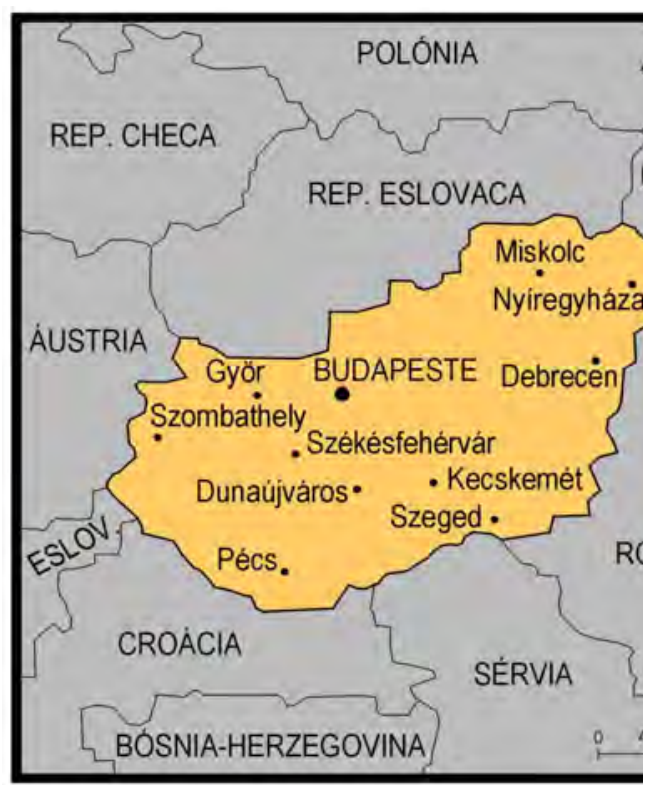




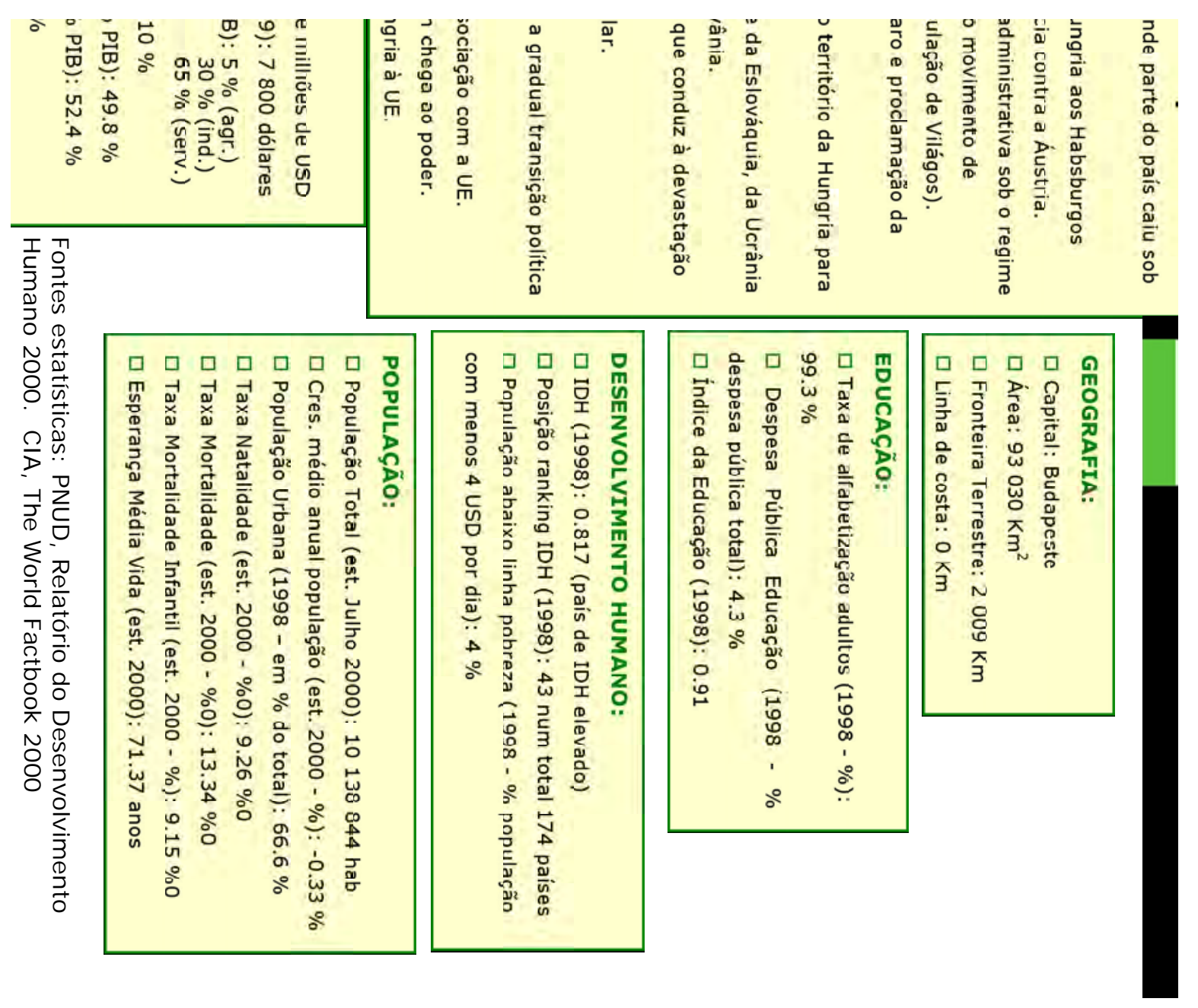


eilcieilia pivuulivas.

${ }^{3}$ A descentralização da propriedade pode ser vista como uma fonte de saneamento financeiro, através da entrada de dinheiro dos cofres do Estado.

4 O "capitalismo popular" relaciona-se com a implementação de um sistema, dentro de uma economia de mercado livre, segundo o qual a
URSS e pelos seus satélites da Europa Oriental, constituía um bloco económico c como resposta ao Plano Marshall e à objectivo desta instituição era, a prazo, 1 a integração total das economias dos Membros, nomeadamente recorrendo: Internacional do Trabalho (DIT). Foi e) Junho de 1991.

\section{Bibliografia}

BRUSZT, L. "The Russian Lesson: A Market Economy Needs an Effective State". In: Transition Newsletter, May-July 2000, The World Bank Group/The William Davidson Institute, Stockholm, 2000, pp. 20-22.

BUITER, W. "Challenges of the Second Transition Decade in Russia". In Transition Newsletter, August-October 2000, The World Bank Group/ The William Davidson Institute, Stockholm, 2000, pp. 24-26.

COLLINS, P. Ideology After the Fall of Communism - The Triumph of Liberal Democracy?, Boyars/ Bowerdean, London, 1992, pp. 135.

COMISSÃO EUROPEIA. Agenda 2000: Parecer da Comissão relativo ao pedido de adesão da Hungria à União Europeia, Boletim da União Europeia Suplementa 2/99, Serviço das Publicações Oficiais das Comunidades Europeias, Luxemburgo, 2000.
EBRD. Transition Report 2001, Ex Summary, London, 2001, pp. 8.

EBRD. Transition Report 2000, Ex Summary, London, 2000, pp. 6.

GOMULKA, S. “Ten Years in Retrospect: of Successful Macroeconomic Polic Transition Newsletter, August-October 2 World Bank Group/The William D Institute, Stockholm, 2000, pp.15-19.

HAVRYLYSHYN, O. “Determinants of G Transition Countries". In: Finance \& Devt - a Quarterly Magazine of the IMF, Jur Volume 36, Number 2, 1999, pp. 1-5.

ICEP. Hungria: um país, um mercado, 1999.

KONTLER, László. Millennium in Central a History of Hungary, Atlantisz Publishin Budapest, 1992. 

